University of Nebraska - Lincoln

DigitalCommons@University of Nebraska - Lincoln

Microcomputer Based Digital Image Processing System Developed To Count And Size Laser-Generated Small Particle Images
K. D. Ahlers
D. R. Alexander

Follow this and additional works at: https://digitalcommons.unl.edu/mechengfacpub

Part of the Mechanics of Materials Commons, Nanoscience and Nanotechnology Commons, Other Engineering Science and Materials Commons, and the Other Mechanical Engineering Commons

This Article is brought to you for free and open access by the Mechanical \& Materials Engineering, Department of at DigitalCommons@University of Nebraska - Lincoln. It has been accepted for inclusion in Mechanical \& Materials Engineering Faculty Publications by an authorized administrator of DigitalCommons@University of Nebraska Lincoln. 


\section{Microcomputer based digital image processing system developed to count and size laser-generated small particle images}

\author{
K. D. Ahlers* \\ D. R. Alexander \\ University of Nebraska \\ Mechanical Engineering Department \\ Lincoln, Nebraska 68588-0525
}

\begin{abstract}
A microcomputer-based digital image processing system has been developed to count and size laser-generated small particle images. Processing rates of 5 to 600 frames per minute were achieved by utilizing a real-time digital image processor. Particles from 7 to $700 \mu \mathrm{m}$ in the plane of focus were counted and sized. A major emphasis in this work was to determine the basic problems and limitations involved with using a digital image processing scheme to accurately size particles. Areas that were investigated include the effect of the threshold level on measured particle size, particle boundary diffraction graylevel gradients, and geometric nonlinearities introduced by the vidicon camera. A Laser Electro-Optics Ltd. calibration reticle containing simulated particles from 5.29 to $92.75 \mu \mathrm{m}$ in diameter was used as the basis for an in-depth calibration process. It was determined that various inherent problems with image processing systems limit their accuracy unless compensation is made. Decalibration techniques were used to correct for these inaccuracies. After correction, an average error of less than $1.0 \%$ was found for 25 to $100 \mu \mathrm{m}$ particles. A $2.8 \%$ error was found in the experimentally determined distribution of $52.8 \mu \mathrm{m}$ polystyrene microspheres.
\end{abstract}

Subject terms: particle sizing; photographic droplet sizing; direct optical imaging; realtime droplet sizing; optical particle sizing; image processing of droplets.

Optical Engineering 24(6), 1060-1065 (November/December 1985).

\section{CONTENTS}

1. Introduction

2. Experimental apparatus and procedure

2.1. Laser imaging device

2.2. Digital image processor

2.3. Segmentation technique

2.4. Calibration technique

3. Results

3.1. System performance

3.2. Calibration accuracy

3.3. Benchmark test

4. Conclusions

5. Acknowledgments

6. References

\section{INTRODUCTION}

Rapid advances in fast analog-to-digital converters and the development of real-time image processors combined with laser imaging systems offer new capabilities for studying atomization, vaporization, and combustion processes.

The use of digital image processing techniques for making laboratory measurements has been explored by several investigators. As early as the 1950s hard-wired cell counting machines were devised by Langercrantz in Scandinavia and Robert and Young at University College in London. ${ }^{1}$ Laboratory recognition systems based on general-purpose programmable computers evolved as minicomputer technology became available.

Several image processing systems have been proposed to count and classify particles. Williams et al. ${ }^{2}$ produced algorithms for mea-

* Present address: 5400 Haymeadow Lane, Apt. 1B, Peoria, IL 61615.

Paper 2079 received Oct. 10, 1984; revised manuscript received May 22, 1985; accepted for publication May 30, 1985; received by Managing Editor June 17, 1985.

$\odot$ for publication May 30, 1985; received by Managing Editor
$\odot 1985$ Society of Photo-Optical Instrumentation Engineers. suring spatial parameters of dust particles. Another example is a hard-wired scanner connected to a digital computer by Sato et al. ${ }^{3}$ This system, as with most other early work, operated in an off-line mode, thus requiring the digitized picture to be punched onto paper tape or recorded on magnetic tape or disk. Simmons and Lapera ${ }^{4}$ described a more modern "high speed spray analyzer" that was capable of automatically sizing a fuel nozzle test in under one hour. Algorithms for analysis of fuel spray images in various background conditions were presented by Oberdier. ${ }^{5}$ Weiss et al. ${ }^{6}$ published work on automating a fluid particle imaging system. This scheme assumed spherical particles (circular images) and determined focus criteria from boundary gray-level gradients. Other on-line sizing systems have been reported by Tishkoff, ${ }^{7}$ Toner et al., ${ }^{8}$ Hotham, ${ }^{9}$ and Fleeter et al., ${ }^{10}$ and for the Bete Droplet Analyzer. ${ }^{11}$

Although commercial and laboratory counting and sizing systems are available, apparently very few data concerning the accuracy and calibration of aut omated counting and sizing systems have been published. Many inherent accuracy implications of using an automated digital image sizing system exist. These include boundary diffraction gray-level gradients, geometric nonlinearity, depth of field corrections, and photometric nonlinearities. Since calibration benchmarks along with errors or estimation of errors have not been reported, the accuracy of most digital image particle sizing systems remains unclear even for ideal counting conditions. The accuracy of size measurements for nonideal counting conditions and where corrections for depth of field factors must be applied are even more questionable. In addition, most published processing times for multigray-level systems (gray-level resolution $>1$ bit) have been on the order of minutes per frame. This high processing time overhead precludes the analysis of large numbers of frames, which is necessary to obtain a statistically valid sample.

The present work was undertaken to develop an image processing system to count and size small particles. The primary thrust of this research was to investigate and report problems and limitations 


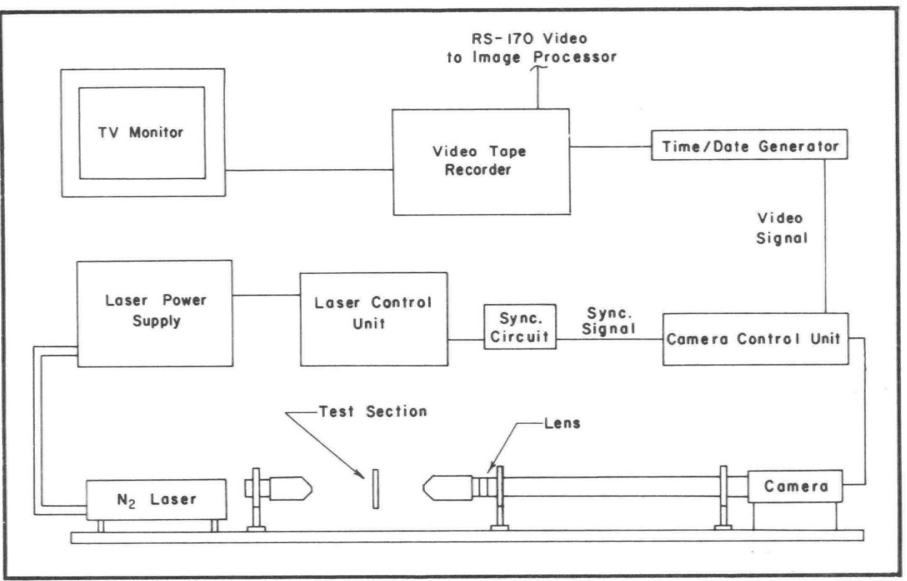

Fig. 1. Block diagram of laser imaging system.

involved in the application of digital image processing to particle sizing work. Several areas that affect accuracy have been identified and results presented. Current research indicates the accuracy of imaging-based sizing systems are subject to significant errors unless provisions are made to correct for such factors as boundary diffraction gradients affecting diameter measurements, geometric nonlinearities of vidicon systems, depth of field determination, focus criteria, and proper reporting of calibration techniques.

In addition to studying accuracy factors and developing detailed calibration techniques under ideal counting conditions, another requirement was to provide fast processing times. The current project deals with measuring static images in the plane of focus, such as calibration reticles and particles placed between glass microscope slides. The current research serves to document the accuracy and calibration of the automated particle counting and sizing software and the associated laser imaging system. Research is in progress to extend the baseline measurements to real sprays.

\section{EXPERIMENTAL APPARATUS AND PROCEDURE}

\subsection{Laser imaging device}

The particle images are generated via a Laser Holography, Inc., laser imaging device. A very early version of this optical imaging system is described by Hotham. ${ }^{9}$ A $337 \mathrm{~nm} 20 \mathrm{~kW}$ pulsed nitrogen laser is used to illuminate the test section that contains the particles. A diffraction limited plano-convex lens focuses the beam onto an ultraviolet-sensitive Cohu vidicon tube. The camera and laser are synchronized together at 30 or $60 \mathrm{~Hz}$. The RS-170 standard composite video is routed through a time/date generator (Panasonic WJ-810) and optionally recorded on a video cassette recorder (RCA VET 650) before being passed to the image processing system. A block diagram outlining the laser imaging device is shown in Fig. 1.

\subsection{Digital image processor}

A Recognition Concepts, Inc., Trapix 55/32 real-time image processor is used to digitize and store the video images. An 8 bit, $8 \mathrm{MHz}$ V/D (video-to-digital) converter digitizes the video source into image memory. Image memory consists of 1.0 Mbyte of RAM, which provides space for four $512 \times 512 \times 8$ bit digital images. The image processor includes a $12 \mathrm{Mbyte} / \mathrm{s}$ pipeline image processor (PIP). The PIP provides the programmer 32 logical and arithmetic opcodes that can be used to perform frame-to-frame addition, subtraction, multiplication, and conditional writes (such as thresholding) at video rates.

A Digital Equipment Corp. LSI-11/02 CPU acts as a host for the image processor. The counting and sizing program executes under the RT-11 operating system on the LSI-11CPU. Appropriate calls are made to the image processor to access the image RAM, which contains the $512 \times 512$ array of gray levels. Figure 2 shows the relationship of the host CPU and image processor.

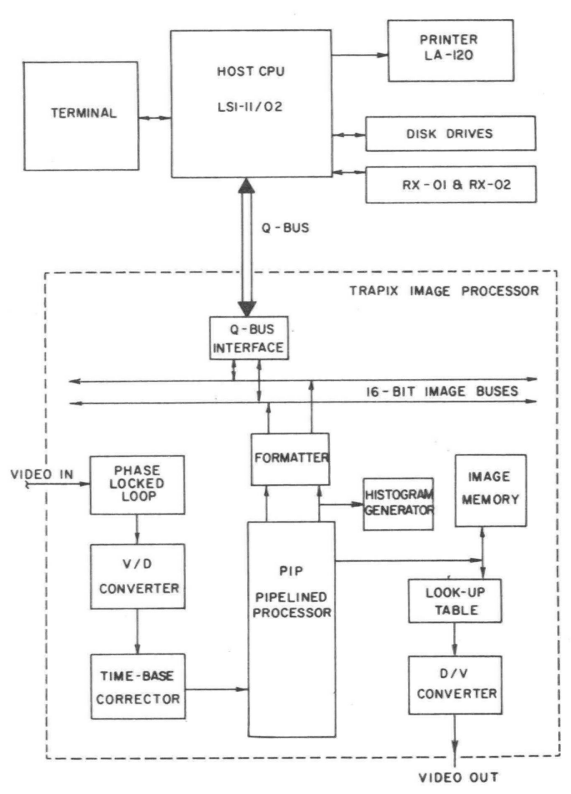

Fig. 2. Relationship of Trapix image processor and host computer.

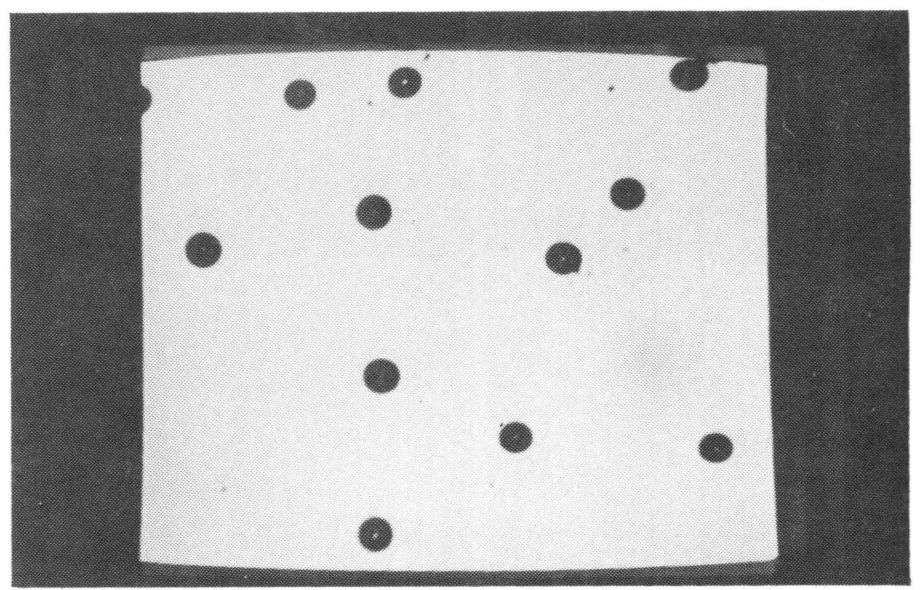

Fig. 3. Typical laser image containing eleven $50 \mu \mathrm{m}$ particles.

\subsection{Segmentation technique}

As with all previously proposed pattern recognition schemes, ${ }^{12}$ the solution of this recognition problem was based on a priori postulates. For example, in this work it is assumed that the video scene will consist of dark particle shadows on a light background. The particles can be of any shape and may contain interior voids, but must be continuous (not fragmented). A representative frame containing eleven $50 \mu \mathrm{m}$ in-focus particles is shown in Fig. 3.

A pattern recognition scheme was developed that is able to count and size images, given the above a priori assumptions. The first step is threshold-inversion preprocessing. Here the background and a limited amount of noise are eliminated by conditionally writing each pixel based upon its gray-level value. The simplest form of this is constant threshold:

$$
\begin{aligned}
\operatorname{pixel}(\mathrm{i}, \mathrm{j}) & =0 & & \text { if } \operatorname{pixel}(\mathrm{i}, \mathrm{j})<\text { constant } \\
& =\operatorname{pixel}(\mathrm{i}, \mathrm{j}) & & \text { if } \operatorname{pixel}(\mathrm{i}, \mathrm{j}) \geq \text { constant }
\end{aligned}
$$

The gray levels are inverted at the same time to preserve the graylevel intensity of the particle images. The result of the threshold 


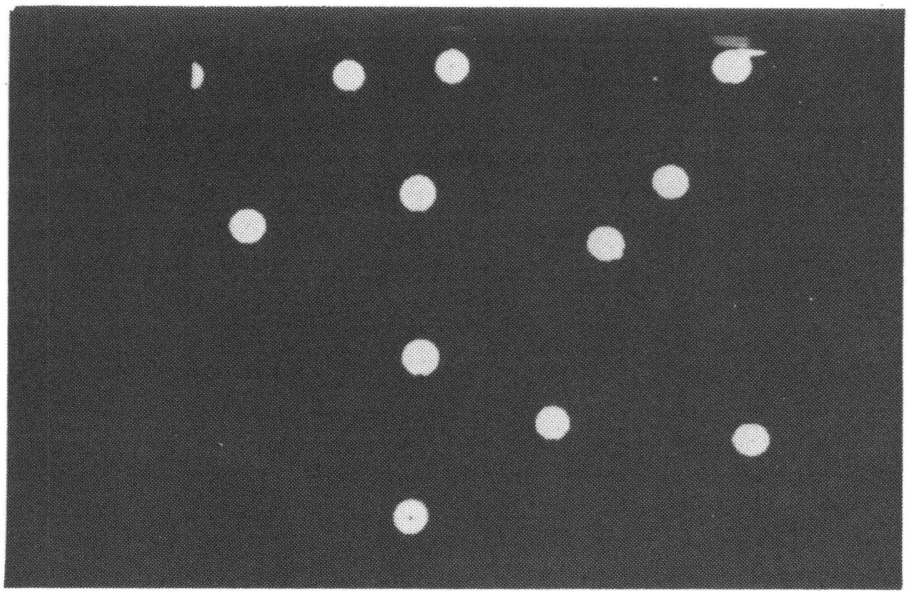

Fig. 4. Example of threshold operation (threshold $=50$ ).

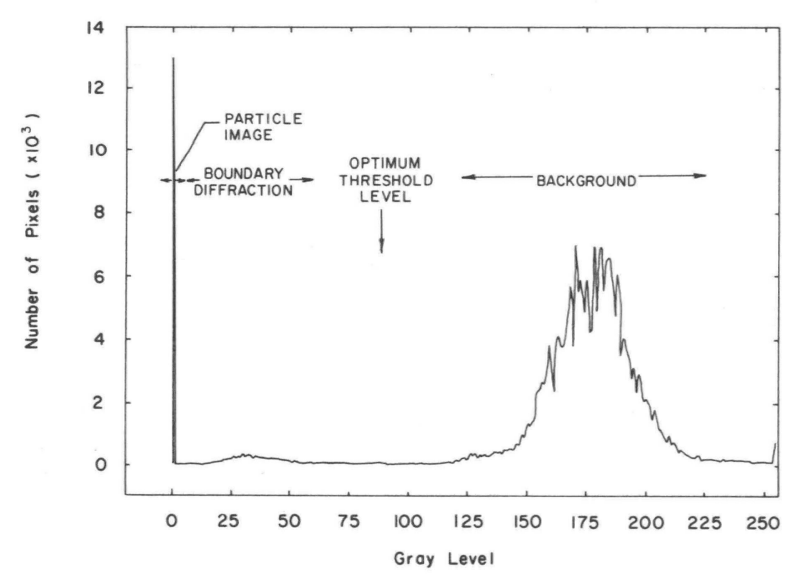

Fig. 5. Gray-level histogram of Fig. 3.

operation is presented in Fig. 4. The threshold constant can be fixed or adjusted automatically.

The automatic threshold constant determination is based on generating a gray-level histogram. As can be seen in Fig. 5, the image to be analyzed contains the nearly black particles, gray diffraction pattern edges, and a light background. The threshold constant is set by selecting a value between the edge level and the background level. Automatic threshold level determination can be accomplished in under $100 \mathrm{~ms}$ by utilizing the Trapix hardware histogram generator and an appropriate algorithm that searches the histogram for the midpoint between the background and edge gray levels.

The third preprocessing feature investigated was background thresholding. A representative background frame, including nonuniformities in illumination, is stored, and incoming particle images are thresholded against this frame on a pixel-by-pixel basis. This preprocessing can help compensate for nonuniform backgrounds. Execution time for the process is $33.3 \mathrm{~ms}$, including digitizing time.

With the frame preprocessed, a line segmentation technique is used to identify and measure the particle images. The image is scanned on a line-by-line basis and run-end coded. ${ }^{13}$ Originally developed for data compression, the underlying line segment principle ${ }^{14}$ is used to identify which line segments belong to which particle. The principle of the underlying line segment technique is shown in Fig. 6.

"If any portion of a line segment falls under a line segment on the raster line above it, that segment belongs to the previous particle and is included in the measurements. In Fig. 6, the middle portion of segment 2 falls below the end points of segment 1 . Hence, segment 2

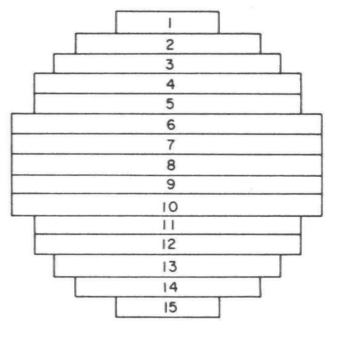

Fig. 6. Circular particle image demonstrating the shape of a digital image boundary and the "underlying line segment principle" sizing method.

is included in the object that was started at segment 1 . If no segment on the line above matches, the segment in question is the beginning of a new object. Segment 1 started the object shown in Fig. 6.

Measurements that are made on each particle image are $\mathrm{x}$ and $\mathrm{y}$ extent, area, perimeter, average gray level, and $x-y$ spatial coordinates (position). Aspect ratio, circularity, and rectangularity are shape factors calculated from the primary measurements.

The particle diameters are then grouped into size ranges and summed over as many frames as needed. At the conclusion of a test, the size groupings are printed out, along with the various calculated mean diameters. Figure 7 is an example of a typical summary data sheet produced in a test involving polystyrene microspheres.

\subsection{Calibration technique}

To ensure that the results produced are accurate and repeatable, an extensive calibration process was carried out. The basis for this calibration was a Laser Electro-Optics Ltd. calibration reticle RR50.0-3.0-0.08-102-\#114. ${ }^{15}$ This calibration standard has been gaining widespread acceptance in the particle sizing field. Shown in Fig. 8, the reticle contains 23 different simulated particles of chrome thin film photoetched on a glass slide. The particles range in size from 5.92 to $92.75 \mu \mathrm{m}$.

A major part of the calibration work was centered on the threshold-level/size-change phenomenon. No previously published work indicated how to correct for the relationship between threshold level and size change. The diffraction pattern around objects in the plane of focus produces a gray-level gradient. Because thresholding (and most other preprocessing techniques) cuts the gradient at one particular gray level, the experimentally measured diameter changes with threshold level. Figure 9 demonstrates edge diffraction and the effect of varying threshold levels when experimentally measuring particle diameters. At high threshold levels, more of the diffraction pattern is measured, causing the particle to appear larger than its true size. Conversely, low threshold levels will underestimate particle diameter.

Five hundred ninety-two video frames of the Laser Electro-Optics reticle quality control field were analyzed at 37 threshold levels. The measured diameters were compared with the actual diameters as reported on the reticle data sheet. ${ }^{15}$ The effect of changing the threshold level is illustrated in Fig. 10. It was found that the slope of the size versus threshold level lines is nearly constant for all sizes of particles. Because this slope is constant, it can be inferred that the width of the boundary diffraction gradient region does not vary with particle size. When the diameter of the image to be measured is less than twice the width of the boundary diffraction gradient, the error in measured diameters will be very high. It was found that the accuracy in determining particle size decayed rapidly for particles less than $10 \mu \mathrm{m}$ in diameter. Particle images less than $10 \mu \mathrm{m}$ have edge breakup during the thresholding process. The slope and intercept of the size/threshold level line was used to determine the optimum threshold level that produced the minimum overall error in measuring 10 to $93 \mu \mathrm{m}$ particle images.

Figure 11 demonstrates the behavior of the slope of the sizechange line for different sizes of particles. Since there seemed to be 


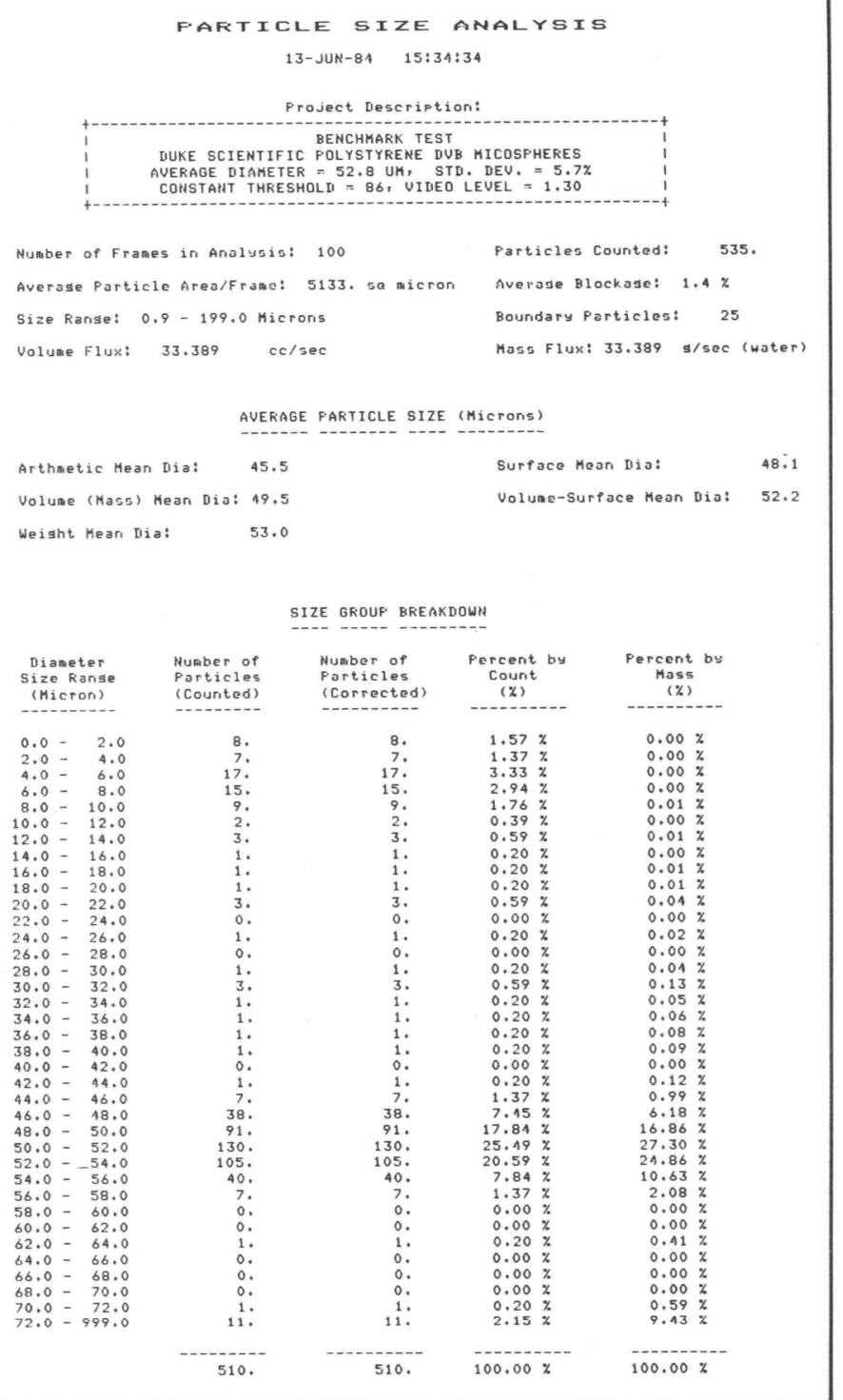

Fig. 7. Sample of particle counting and sizing program summary sheet.

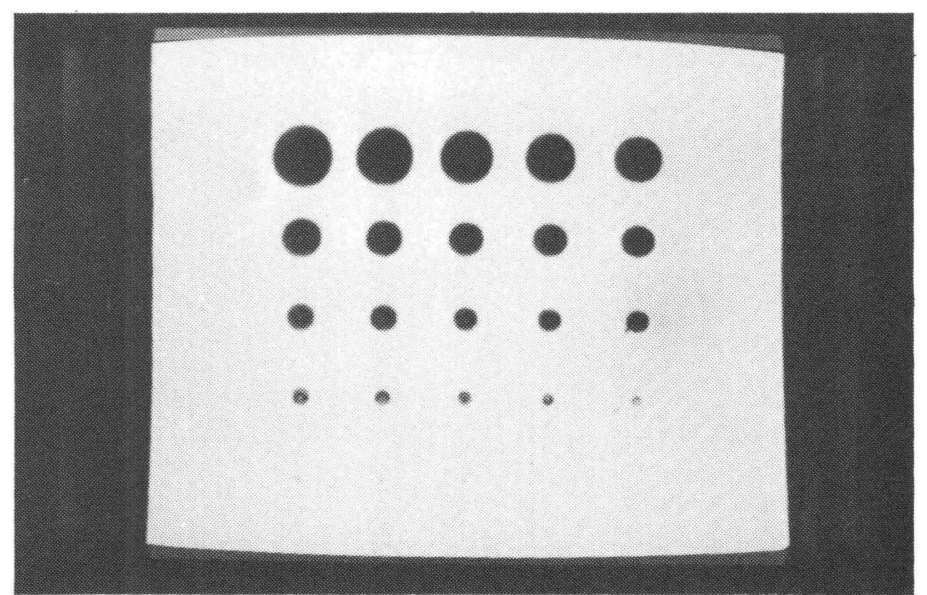

Fig. 8. Twenty-three particle imaging field in Laser Electro-Optics calibration reticle.

more or less random correlations in the slope of the size-change line and particle size, the average value was used in this work. Figure 12
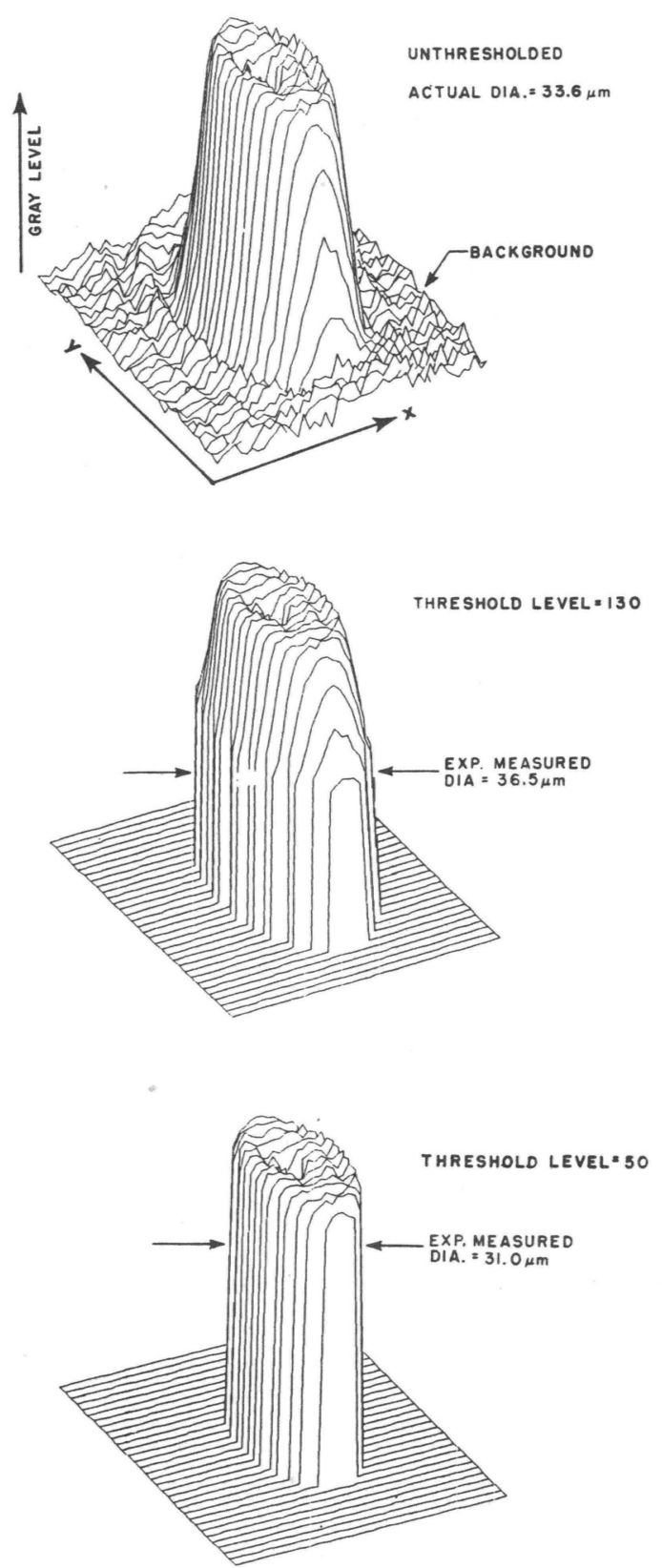

Fig. 9. Effect of threshold level on boundary gradient and diameter (gray levels inverted).

shows similar random correlation of threshold level and particle size. Thus, it was determined that the optimum threshold level was not a strong function of particle size and that one average threshold level can be used for all particle sizes with little error resulting. In addition, a threshold size correction function was formulated and put in software to allow any threshold level to be used without an appreciable sacrifice in accuracy. This allows the setting of the threshold at any arbitrary level to accommodate special optical conditions, such as a dark background caused by large numbers of extraneous particles far out of the plane of focus. If a threshold level other than the optimum is selected, the slope of the measured size versus threshold level line (Fig. 10) is used to correct the measured sizes for the selected threshold level. Figures 13 and 14 demonstrate the typical measured errors with these assumptions applied.

Another factor that affects the accuracy of imaging systems is geometric nonlinearity. Geometric nonlinearity was a common prob- 


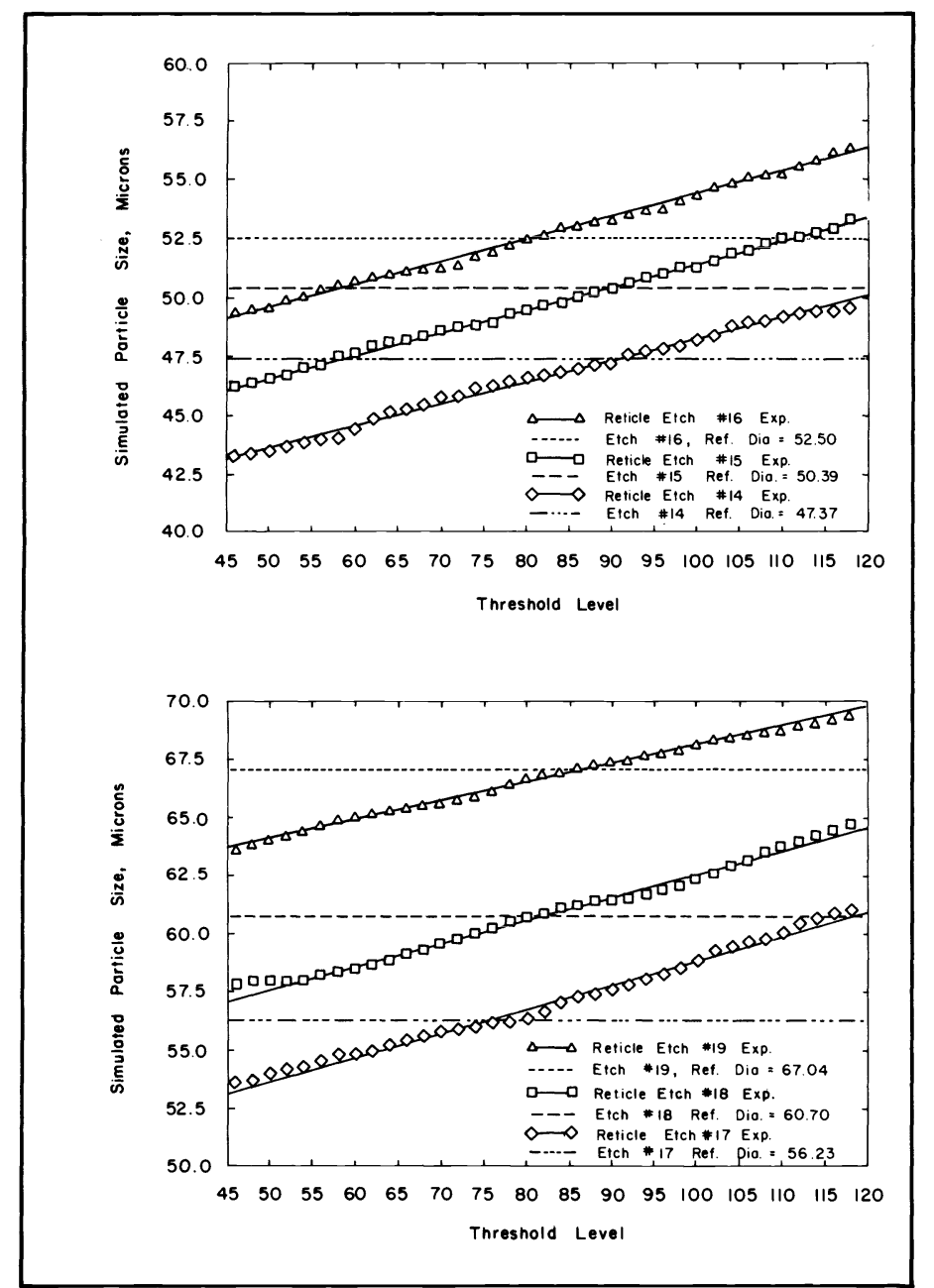

Fig. 10. Effect of threshold level on experimentally measured diameter.

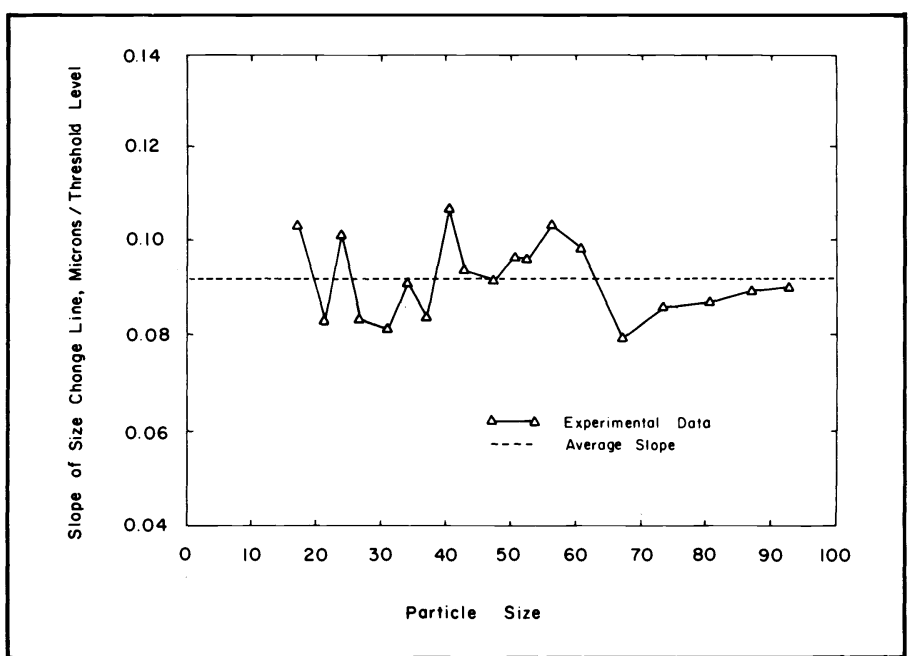

Fig. 11. Slope of the size-change line as a function of particle size.

lem of digital image processing systems used for planetary probes at Jet Propulsion Laboratory. ${ }^{14}$ Geometric nonlinearity manifests itself as a spatially varying pixel magnification factor. Pixel magnification (e.g., $\mu \mathrm{m} /$ pixel) was measured to vary up to $22 \%$ over the field of view with the camera used for this research. While the average local variation in magnification factor for a given camera may not be this

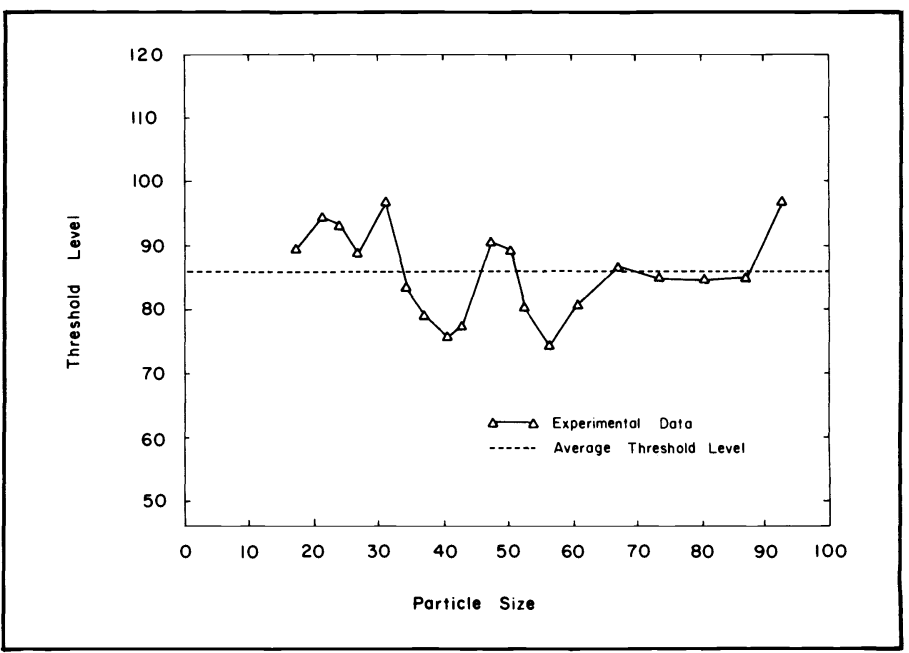

Fig. 12. Optimum threshold level as a function of particle size.

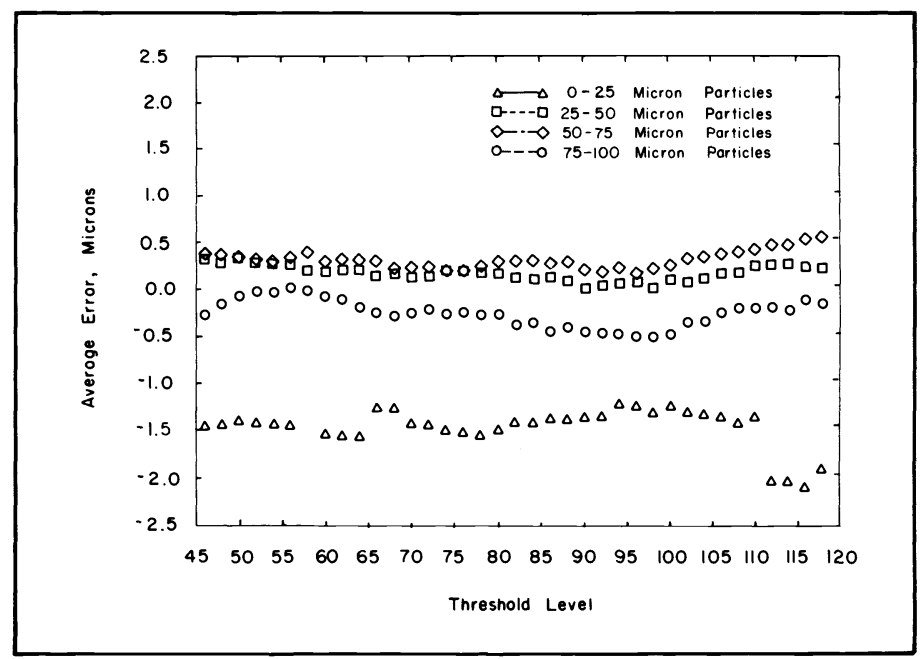

Fig. 13. Average error in micrometers as a function of threshold level.

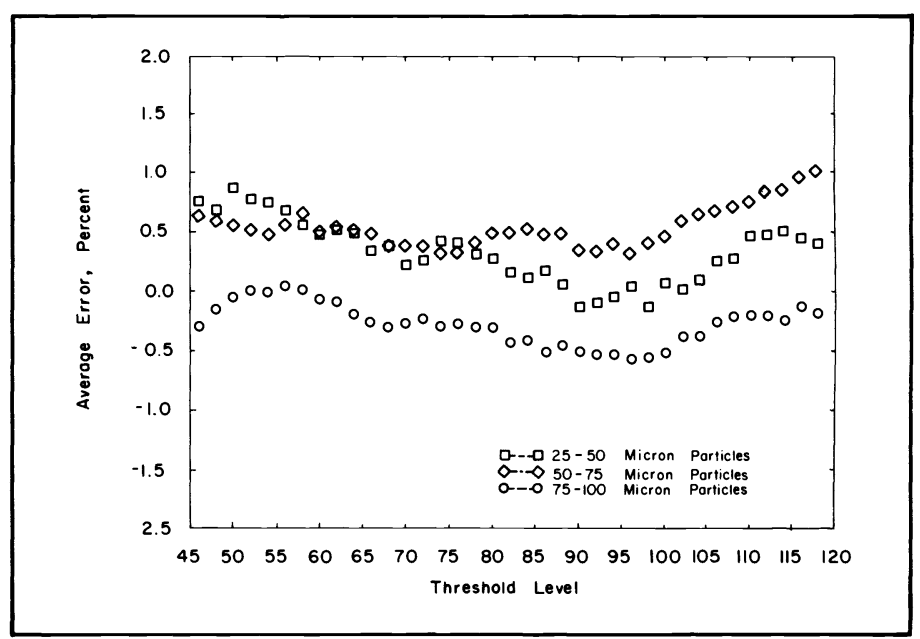

Fig. 14. Average error in percent as a function of threshold level.

high, it was demonstrated that the spatially varying pixel size produced by the currently used vidicon-type camera can introduce significant errors into particle size measurements. It is expected that a 
solid-state detector camera, such as a CCD, would significantly reduce this problem.

The geometric nonlinearity produced by the camera was corrected in this investigation by a detailed geometric decalibration process. First, the local pixel magnification factor was measured at various points within the field of view by use of a comparator reticle. A least-squares best-fit function was then written to approximate the magnification at any given $x, y$ location. Each time a particle is located by the analysis program, the coordinates are input into the function, and the pixel magnification factor for the center coordinates is calculated and then used to determine the actual size of the particle. In this way, the error introduced by geometric nonlinearity has been minimized.

\section{RESULTS}

\subsection{System performance}

The digital image processing system has performed successfully when counting and sizing static particle images and polystyrene microspheres in the plane of focus. The program is $90 \%$ coded in FORTRAN IV, thereby making it easy to modify to meet the special data requirements of each user.

Analysis time has been optimized to allow the counting of the large number of frames necessary in a statistically valid sample. Typical processing rates range from 5 to 600 frames per minute depending upon particle density. A worst-case frame requires $12 \mathrm{~s}$ to count and size 250 particles. (Analysis time will be reduced by a factor of 7.5 upon completion of the upgrading of the computer to an LSI-11/73.) If no particles are present in a frame, only $67 \mathrm{~ms}$ are required for analysis.

\subsection{Calibration accuracy}

By incorporating threshold level correcting functions and geometric decalibration techniques, the overall accuracy of the counting and sizing techniques was improved. The average error found in the calibration data was $0.87 \mu \mathrm{m}$, with standard deviations below $0.5 \mu \mathrm{m}$. Overall errors for 25 to $100 \mu \mathrm{m}$ particle images were less than $1 \%$, with smaller particles in the 0 to $25 \mu \mathrm{m}$ range averaging $17 \%$ error. The average error for large particles was actually less than the system resolution of $1.85 \mu \mathrm{m}$. This is possible since results were averaged over many particles. The average error increased very rapidly as the system resolution was approached. Figures 13 and 14 show that calibration techniques used in this work kept errors under $1 \%$ for 25 to $100 \mu \mathrm{m}$ particles, and in all cases there was less than $2.0 \mu \mathrm{m}$ total overall error. The data given in Figs. 13 and 14 have been corrected for threshold level using the technique described in Sec. 2.4. This demonstrates that any threshold level can be selected with relatively low error.

\subsection{Benchmark test}

In order to test the calibration and check repeatability, benchmark tests were performed. Duke Scientific polystyrene divinylbenzene microspheres (average diameter $=52.8 \mu \mathrm{m}$, standard deviation $=5.7 \%$ ) were used as reference particles. ${ }^{16}$ One hundred frames were analyzed for a total of 510 particles counted. The size distribution that was experimentally determined is shown in Fig. 15 plotted against the theoretical normal distribution. The method used in determining the manufacturer's published average diameter is not clearly specified in Ref. 16. If the published diameter is taken to be exact, ${ }^{16}$ then Fig. 15 shows that the present sizing system underestimated the actual particle sizes by approximately $1.5 \mu \mathrm{m}$, or $2.8 \%$.

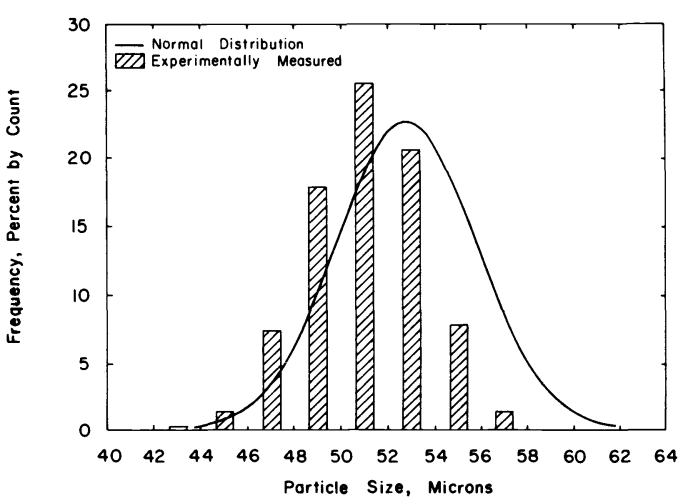

Fig. 15. Size distribution for polystyrene microspheres.

\section{CONCLUSIONS}

A fast, accurate system for counting and sizing in-focus particles in the 7 to $700 \mu \mathrm{m}$ size range has been developed, calibrated, and tested. This system is capable of processing 5 to 600 frames per minute. Best-case calibration reticle data indicate less than $1 \%$ error for 25 to $100 \mu \mathrm{m}$ particles, and actual benchmark tests (Fig. 14) show approximately a $3 \%$ error for $52.8 \mu \mathrm{m}$ microspheres. For sizes smaller than $25 \mu \mathrm{m}$ the accuracy decays, and errors of $\pm 10 \%$ can be expected for objects below $10 \mu \mathrm{m}$. This is limited by the system resolution and diffraction problems.

\section{ACKNOWLEDGMENTS}

The author wishes to express his appreciation to the following groups that have supported this research: Amoco Foundation Young Faculty Development Grant, University of Nebraska Engineering Research Center, and University of Nebraska-Lincoln Mechanical Engineering Department.

\section{REFERENCES}

1. B. L. Wignall, Laboratory Equipment Digest 13, 67 (March 1975).

2. D. H. Williams, C. W. Yip, and C. McDonald, IEEE Comp. Soc. Conf. on Pattern Recognition and Image Processing, pp. 336-339 (1981).

3. M. Sato, K. Shimizu, and T. Sakai, J. Inst. Fuel 50(19), 18 (1977).

4. H. C. Simmons and D. L. Lapera, "A High-Speed Spray Analyzer for Gas Turbine Fuel Nozzles," presented at ASME Gas Turbine Conf. (March 1969).

5. L. M. Oberdier, ASTM Stand. Tech. Publ. No. 848, p. 123 (1984).

6. B. A. Weiss, P. Derov, D. DeBiase, and H. C. Simmons, Opt. Eng. 23(5), 561 (1984).

7. J. M. Tishkoff, Proc. 2nd Int. Conf. on Liquid Atomization and Spray Systems, p. 245, Conference Committee, c/ o E. Johansen Crosby, Dept. of Chemical Engineering, Univ. of Wisconsin, Madison, WI 53706 , (1982).

8. M. C. Toner, M. Dix and H. Sawistowski, J. Phys. E:2, 1 (1978)

9. G. A. Hotham, Nat Bur. Stand. Spec. Publ. 412, pp. 97-126 (1974).

10. R. Fleeter, R. Toaz, and V. Sarohia, ASME Paper 82-WA/HT-23, pp. 1-8 (1982).

11. Bete Fog Nozzle Inc. Booklet No. 1001, pp. 1-4 (1981).

12. V. A. Kovalevsky, Image Pattern Recognition, Springer-Verlag, New York (1980).

13. C. S. Ow and R. I. Crane, J. Inst. Energy 54, 119 (1981)

14. K. R. Castleman, Digital Image Processing, pp. 317-318, Prentice-Hall, Englewood Cliffs, N.J. (1979).

15. E. D. Hirleman, "Calibration Standard Reticles for Particle Sizing Instruments," Laser Electro-Optics Ltd. product announcement (1982).

16. "Analytical Reference Particles-Bulletin 83," p. 7, Duke Scientific Corp. (1983). 